\begin{tabular}{|c|c|c|}
\hline \multirow{3}{*}{$\begin{array}{r}\text { Case Reports in } \\
\text { Gastroenterology }\end{array}$} & \multirow{2}{*}{\multicolumn{2}{|c|}{ Case Rep Gastroenterol 2017;11:440-445 }} \\
\hline & & \\
\hline & $\begin{array}{l}\text { DOI: 10.1159/000479314 } \\
\text { Published online: August 8, } 2017\end{array}$ & $\begin{array}{l}\text { (c) } 2017 \text { The Author(s) } \\
\text { Published by S. Karger AG, Basel } \\
\text { www.karger.com/crg }\end{array}$ \\
\hline & \multicolumn{2}{|c|}{$\begin{array}{l}\text { This article is licensed under the Creative Commons Attribution-NonCommercial } 4.0 \\
\text { International License (CC BY-NC) (http://www.karger.com/Services/OpenAccessLicense). } \\
\text { Usage and distribution for commercial purposes requires written permission. }\end{array}$} \\
\hline
\end{tabular}

\title{
Drug-Induced Autoimmune Hepatitis following Treatment with Zoledronic Acid
}

\author{
Jenny Sarah Schneider ${ }^{a} \quad$ Matteo Montani ${ }^{b} \quad$ Felix Stickel $^{a, c}$ \\ ${ }^{a}$ Hepatology Unit, Klinik Beau-Site, Hirslanden Bern, Bern, Switzerland; ${ }^{b}$ Institute of

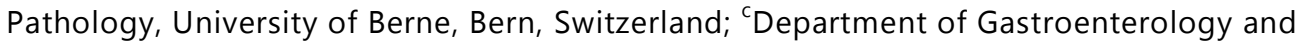 \\ Hepatology, University Hospital Zurich, Zurich, Switzerland
}

\section{Keywords}

Acute hepatitis · Drug-induced autoimmunity · Immunosuppression · Adverse hepatic drug reactions · Drug-induced liver injury

\begin{abstract}
Adverse drug reactions are among the most frequent side effects of synthetic and complementary alternative drugs and represent the premier causes of license revocations and acute liver failure. Drug-induced liver injury can resemble literally any other genuine liver disease and usually responds well to drug dechallenge. However, in some cases autoimmune-like hepatitis can evolve, requiring short- and sometimes long-term immunosuppression. Here, we present the hitherto first case of autoimmune-like hepatitis following treatment with zoledronic acid.

(C) 2017 The Author(s) Published by S. Karger AG, Basel
\end{abstract}

\section{Introduction}

Bisphosphonates are the first-line treatment in women with postmenopausal osteoporosis, with a well-documented benefit in the prevention of spontaneous fractures and improvement of bone density [1]. Severe adverse drug reactions are rare and the most common side effects include nausea, myalgia, and headaches. 
Along with the widespread use of zoledronic acid (ZA), case reports describe druginduced liver injury (DILI) causally ascribed to its administration [2-4]. In all cases, acute hepatitis with markedly elevated aspartate aminotransferase, alanine aminotransferase, and gamma-glutamyl transpeptidase following ZA administration was noticed, which rapidly subsided upon cessation of treatment. Prolonged adverse hepatic reactions due to ZA not responding to dechallenge, including autoimmune hepatitis (AIH), have not been observed to date.

Here, we present the case of a female patient who developed AIH after intravenous treatment with ZA requiring immunosuppressive treatment to reach stable remission.

\section{Case Report}

A 73-year-old female patient was referred to our outpatient liver clinic with fatigue, pruritus, generalized arthralgia, and acute hepatitis. The medical history had started 5 weeks prior to the first consultation with abdominal discomfort, nausea, diarrhea, and fever of $40^{\circ} \mathrm{C}$ for about 1 week, which had forced her to contact her general practitioner. Recently, the patient had been newly treated with ZA on one occasion for osteoporosis prior to the onset of her clinical symptoms. Apart from the short febrile episode, no further clinical signs of infection or malignancy were evident.

Besides osteoporosis, the past medical history revealed symptoms compatible with irritable bowel syndrome. In addition, a platelet dysfunction termed storage pool deficiency had been established in 2009. The regularly prescribed medication was linaclotid for irritable bowel syndrome, and bisacodyl and Psyllium seed husks for chronic obstipation. Regular or harmful alcohol consumption as well as smoking was convincingly denied. Upon physical examination, no jaundice was recorded, but the patient complained about mild pruritus. Abdominal palpation was unremarkable with no pain or tenderness. No cardiovascular or neurological abnormalities were recorded. Abdominal ultrasound and computed tomography revealed no explanation for the clinical picture. Laboratory results showed elevated aspartate aminotransferase at $349 \mathrm{U} / \mathrm{L}$, alanine aminotransferase at $183 \mathrm{U} / \mathrm{L}$, and gammaglutamyl transpeptidase at $639 \mathrm{U} / \mathrm{L}$. Prior to the current symptoms, serum liver enzyme levels had been repeatedly found to be normal on routine tests.

Serological testing for viral hepatitis, including anti-hepatitis A virus IgM, HBsAg, HBeAg, anti-HBs, anti-HBe, anti-HBc, hepatitis B virus DNA, anti-hepatitis $C$ virus, hepatitis $C$ virus RNA, anti-cytomegalovirus IgM, anti-Epstein-Barr virus IgM, anti-hepatitis E virus IgM/IgG, and human immunodeficiency virus, turned out negative.

The titer of antinuclear antibodies was mildly elevated at 1:80, but the serum IgG level was within normal range $(11.5 \mathrm{~g} / \mathrm{L})$. Other autoimmune markers, including anti-mitochondrial antibodies, liver-kidney-microsomal antibodies, and smooth muscle actin antibodies, were all found to be below the level of detection.

In essence, the working diagnosis was acute DILI presenting with a predominantly cytolytic enzyme pattern, i.e., hepatitis. Initially, liver enzymes showed a moderate decline to a plateau of persistent elevation and a sudden increase after several weeks (Fig. 1). This course together with persistent fatigue and nausea prompted us to perform a percutaneous liver biopsy, which showed features compatible with AIH such as lymphoplasmacellular infiltration, necrosis, and fibrous collapse (Fig. 2).

Based on these findings, drug-induced AIH was assumed. According to the simplified diagnostic criteria for AIH set forth in the paper by Hennes et al. [5], the patient reached 
5 points, which falls behind the definition of definite AIH ( $\geq 7$ points), but the typical histology of our patient was considered clinically decisive for starting therapy with $50 \mathrm{mg}$ of prednisolone daily. Following a rapid improvement both clinically and biochemically (Fig. 1), steroids were tapered at 10 weeks of treatment after biochemical remission. Four weeks after cessation of steroids, the patient showed again rising transaminases, indicating recurrence of hepatitis. Due to marked side effects of steroids during the first course of therapy, budesonide at $3 \mathrm{mg}$ three times a day in combination with azathioprine was started, upon which the patient went into remission. However, she developed nausea and vomiting upon azathioprine and was switched to mycophenolate mofetil, upon which she stayed in remission until recently.

\section{Discussion}

We here present a case of AIH following the intake of ZA, a complication of bisphosphonates which has hitherto not been described. Our patient developed biochemical hepatitis as well as low-level autoantibodies and revealed typical features of autoimmune liver disease on histology. Treatment with steroids and mycophenolate mofetil induced full remission, but the patient required long-term immunosuppression.

During the entire course of the incident, no eosinophilia, jaundice, or coagulopathy was observed, so according to a recent severity classification set forth by the Drug-Induce Liver Injury Network, the patient experienced a mild course of DILI, as there was no significant bilirubin elevation or coagulopathy [6].

DILI is frequent, and hepatitis in this context is a well-described biochemical pattern. In fact, DILI is the most frequent cause of drug withdrawal, and fulminant hepatitis following drugs is the most frequent cause of acute liver failure leading to liver transplantation [7]. While the majority of fulminant cases are related to paracetamol overdose, often with suicidal intention, the remaining cases are mostly due to idiosyncratic drug reactions. The latter are unpredictable and dose-independent and may be related to either toxic or autoimmune pathophysiology.

Regarding the latter, the underlying pathophysiology is believed to relate to a covalent binding of drug metabolite to membrane surface proteins of hepatocytes (commonly a phase I or phase II drug-metabolizing enzyme) to form neoantigens. Subsequent activation of CD8 $\mathrm{T}$ lymphocytes with nonselective antigen receptors leads to a (transient or permanent) loss of self-tolerance and tissue injury [8].

DILI presenting with the biological and/or histological features of AIH is well described along with the intake of minocycline, alpha-methyldopa, or nitrofurantoin, but usually shows a chronic course and may progress to cirrhosis in rare instances [9]. Corticosteroid responsiveness is similar in drug-induced AIH and classical AIH; however, discontinuation of immunosuppression rarely precipitates relapses in the former [8], which regularly occur in the latter upon cessation of therapy [10]. This raises the question whether our patient had in fact true AIH unrelated to any medication, but absence of key criteria of AIH including autoantibodies and elevated IgG levels render this possibility rather unlikely. Simple hepatotoxicity from ZA as previously described also appears to be less likely as the patient relapsed although ZA had been stopped 4 months earlier.

The causality of the adverse hepatic reaction was classified according to the Council for International Organizations of Medical Sciences definitions for acute liver injury and reached a score of 8, which indicates a "probable causality" with the intake of a given medication, and 
only falls short of a "definite causality" ( $>8$ ) since the type of DILI, i.e., autoimmune-like reaction, had not been hitherto described [11].

In conclusion, the presented incident appears to represent a rare case of AIH precipitated by the intake of $\mathrm{ZA}$, requiring immunosuppressive therapy. Therefore, medical prescribers are advised to pay attention to DILI in patients treated with ZA and to consider autoimmune-like features as a possibility.

\section{Statement of Ethics}

Written informed consent was obtained from the patient who agreed to have her medical details submitted for publication anonymously.

\section{Disclosure Statement}

The authors have no conflicts of interest to declare.

\section{References}

1 Black DM, Rosen CJ: Postmenopausal osteoporosis. N Engl J Med 2016;374:254-262.

-2 Polyzos SA, Kountouras J, Anastasilakis AD, Litsas I, Kita M, Arsos G, Moralidis E, Terpos E: Zoledronic acid-induced transient hepatotoxicity in a patient effectively treated for Paget's disease of bone. Osteoporos Int 2011;22:363-367.

3 Lu Y, Pei Y, Shao Y, Yan S, Ma L, Fang F, Jin M, Liu M, Li J, Li C: Hepatotoxicity induced by zoledronic acid in an aged woman with primary osteoporosis. EXCLI J 2013;12:115-117.

4 Jiang Y, Fu Y, Xing XP, Li M, Wang O, Xia WB, Meng XW: Zoledronic acid-induced hepatotoxicity relieved after subsequent infusions in a Chinese woman with glucocorticoid-induced osteoporosis. Eur J Med Res 2015;20:68.

-5 Hennes EM, Zeniya M, Czaja AJ, Parés A, Dalekos GN, Krawitt EL, Bittencourt PL, Porta G, Boberg KM, Hofer H, Bianchi FB, Shibata M, Schramm C, Eisenmann de Torres B, Galle PR, McFarlane I, Dienes HP, Lohse AW; International Autoimmune Hepatitis Group: Simplified criteria for the diagnosis of autoimmune hepatitis. Hepatology 2008;48:169-176.

6 Lo Re V 3rd, Haynes K, Forde KA, Goldberg DS, Lewis JD, Carbonari DM, Leidl KB, Reddy KR, Nezamzadeh MS, Roy J, Sha D, Marks AR, De Boer J, Schneider JL, Strom BL, Corley DA: Risk of acute liver failure in patients with drug-induced liver injury: evaluation of Hy's Law and a new prognostic model. Clin Gastroenterol Hepatol 2015;13:2360-2368.

-7 Ostapowicz G, Fontana RJ, Schiødt FV, Larson A, Davern TJ, Han SH, McCashland TM, Shakil AO, Hay JE, Hynan L, Crippin JS, Blei AT, Samuel G, Reisch J, Lee WM; U.S. Acute Liver Failure Study Group: Results of a prospective study of acute liver failure at 17 tertiary care centers in the United States. Ann Intern Med 2002;137:947-954.

-8 Björnsson E, Talwalkar J, Treeprasertsuk S, Kamath PS, Takahashi N, Sanderson S, Neuhauser M, Lindor K: Drug-induced autoimmune hepatitis: clinical characteristics and prognosis. Hepatology 2010;51: 2040-2048.

-9 De Boer YS, Kosinski AS, Urban TJ, Zhao Z, Long N, Chalasani N, Kleiner DE, Hoofnagle JH; Drug-Induced Liver Injury Network: Features of autoimmune hepatitis in patients with drug-induced liver injury. Clin Gastroenterol Hepatol 2017;15:103-112.e2.

10 Liberal R, De Boer YS, Andrade RJ, Bouma G, Dalekos GN, Floreani A, Gleeson D, Hirschfield GM, Invernizzi P, Lenzi M, Lohse AW, Macedo G, Milkiewicz P, Terziroli B, van Hoek B, Vierling JM, Heneghan MA; International Autoimmune Hepatitis Group (IAIHG): Expert clinical management of autoimmune hepatitis in the real world. Aliment Pharmacol Ther 2017;45:723-732.

11 Danan G, Benichou C: Causality assessment of adverse reactions to drugs - I. A novel method based on the conclusions of international consensus meetings: application to drug-induced liver injuries. J Clin Epidemiol 1993;46:1323-1330. 
Schneider et al.: Drug-Induced Autoimmune Hepatitis following Treatment with Zoledronic Acid

$x$

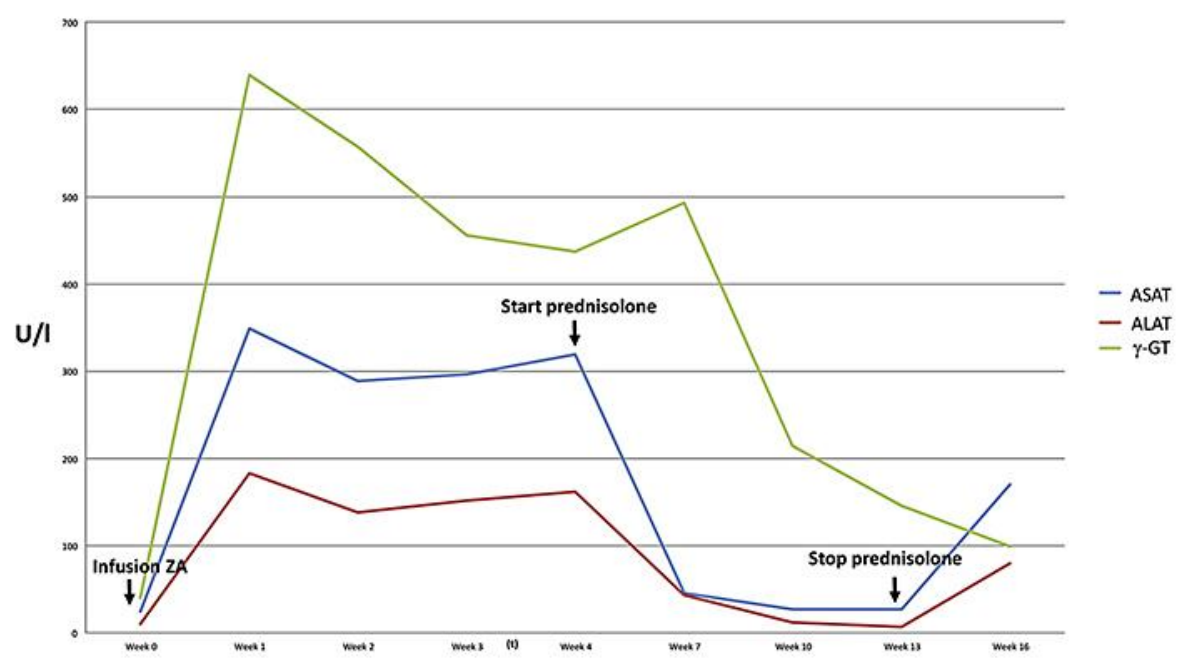

Fig. 1. Course of liver enzymes in a patient with acute hepatitis following treatment with zoledronic acid. Cessation of steroids after reaching normal liver enzyme levels resulted in a relapse of hepatitis. 


\begin{tabular}{|c|c|c|}
\hline \multirow{3}{*}{$\begin{array}{r}\text { Case Reports in } \\
\text { Gastroenterology }\end{array}$} & \multirow{2}{*}{\multicolumn{2}{|c|}{ Case Rep Gastroenterol 2017;11:440-445 }} \\
\hline & & \\
\hline & DOI: $10.1159 / 000479314$ & $\begin{array}{l}\text { (c) } 2017 \text { The Author(s). Published by S. Karger AG, Basel } \\
\text { www.karger.com/crg }\end{array}$ \\
\hline & $\begin{array}{l}\text { Schneider et al.: Drug-In } \\
\text { Zoledronic Acid }\end{array}$ & utoimmune Hepatitis following Treatment with \\
\hline
\end{tabular}

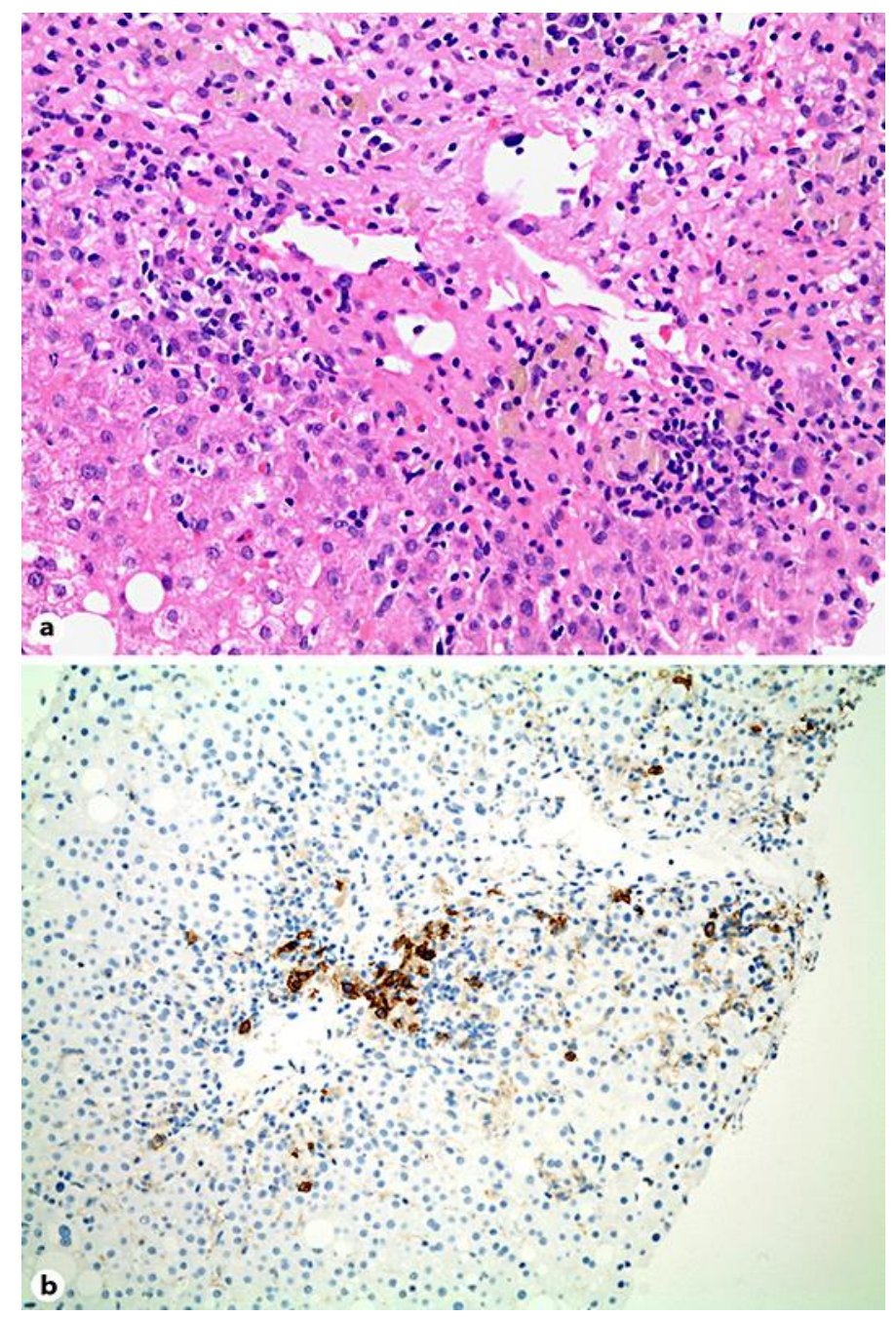

Fig. 2. a Liver biopsy specimen showing severe hepatitis with centrilobular necrosis and fibrous collapse as well as formation of pseudorosettes (hematoxylin/eosin stain, $\times 100$ ). $\mathbf{b}$ Immunohistochemistry stain of a liver biopsy specimen showing plasmacellular infiltration positive for CD38 antigen $(\times 100)$. 